\title{
Evolución favorable a mediano plazo de recién nacidos con bilirrubina elevada
}

Newman T y col. N Engl J Med. 2006;354(18):1889-900.

\author{
Objetivo \\ Comparar la evolución del neurodesarrollo entre niños con bilirrubi- \\ na sérica total (BiT) de $25 \mathrm{mg} / \mathrm{dl}$ o más con la de aquellos sin hiper- \\ bilirrubnemia.
}

Diseño

Estudio de cohorte prospectivo*

Lugar

Sistema proepago Kaiser de California del Norte, EE.UU.

\section{Pacientes}

Los sujetos de estudio fueron 140 niños menores de 30 días con peso $>2000$ grs al nacer $y>36$ semanas de gestación (enrolados entre 1995-1997) o > 34 semanas (entre 1997-1998) con BiT = $25 \mathrm{mg} / \mathrm{dl}$ los cuales recibieron tratamiento con luminoterapia (136) y exanguinotransfusión (5). Se seleccionaron como controles 419 niños seleccionados en forma aleatoria de la misma cohorte de 106.627 recién nacidos vivos entre 1995-1998. Se excluyeron niños con anomalías genéticas o desórdenes neurológicos.

Evaluación de factores pronósticos

Las variables de datos perinatales y de potenciales confundidores* se obtuvieron de reportes médicos o electrónicos y/o mediante cuestionarios a los cuidadores.

\section{Medición de Resultados Principales}

La evaluación formal del desarrollo neurológico fue realizada a una edad promedio de 5 años por examinadores ciegos al grupo de estudio utilizando escalas validadas para tal fin. A su vez se realizaron exámenes neurológicos estandarizados y de impresión general medida mediante una escala de 5 puntos (desde "1" normal a "5" anormal/severa disfunción). En aquellos padres que se negaban al examen se realizó la evaluación interrogando a los padres mediante un cuestionario estandarizado. Adicionalmente se pesquisaron de la base de datos del sistema los episodios de inter- nación debidos a desordenes del sistema nervioso, estrabismo, pérdida de audición, kernicterus, trastornos del sueño, problemas de postura, movimientos o coordinación, imágenes anormales de cerebro o reflejos anormales.

\section{Resultados}

El seguimiento hasta los 2 años de vida se registró en 132 niños del grupo bilirrubina (94\%) y en 372 controles $(89 \%)$, pero la evaluación formal a los 5 años se realizó sólo en $59 \%$ de los casos y $40 \%$ de los controles respectivamente. No hubo casos de kernicterus en ninguno de los grupos. No se encontraron diferencias en la evolución de los grupos en ningunos de los resultados evaluados (Tabla 1).

Tabla 1

\begin{tabular}{|c|c|c|c|c|}
\hline & Grupo control & $\begin{array}{l}\text { Grupo BiT } \\
=25 \mathrm{mg} / \mathrm{dll}\end{array}$ & $\begin{array}{l}\text { Odds Ratio } \\
\text { ajustado*(1695\%) }\end{array}$ & Valor de $\mathbf{p}$ \\
\hline Test WPPSI-R@score global & 104 & 105,9 & $1,4(-2,1-5)$ & 0,42 \\
\hline Test VMI-4@@ (score & 102,1 & 103,3 & $0,6(-2,8-3,9)$ & 0,74 \\
\hline visual-motor, visual y & $\begin{array}{l}105,9 \\
100,4\end{array}$ & $\begin{array}{l}107,5 \\
1013\end{array}$ & $\begin{array}{r}1,2(-3,5-6) \\
-13(-5,6-29)\end{array}$ & 0,60 \\
\hline Ex. neurológico anormal & $12 / 168(7 \%)$ & $3 / 81(4 \%)$ & $0,50(0,14-$ & 0,29 \\
\hline $\begin{array}{l}\text { PEDS ( } \leq \text { una pregunta } \\
\text { como " } s \text { "=dificultad) }\end{array}$ & $\begin{array}{l}56 / 239 \\
(23 \%)\end{array}$ & $\begin{array}{l}26 / 96 \\
(27 \%)\end{array}$ & $\begin{array}{c}1,83) \\
1,2(0,67-2,1)\end{array}$ & 0,56 \\
\hline$\geq 1$ diagnóstico neurológico & $\begin{array}{c}18 / 419 \\
(4 \%)\end{array}$ & $\begin{array}{l}5 / 140 \\
(4 \%)\end{array}$ & $0,78(0,28-$ & 0,63 \\
\hline
\end{tabular}

@ Sigla en inglés de la Escala de Wechsler Prescolar y Primaria revisada; @@ sigla en inglés del test de integración visual-motora versión 4.

\section{Conclusiones}

Los niños con hiperbilirrubinemia dentro de los rangos estudiados no mostraron peor evolución del neurodesarrollo que aquellos sin esta condición.

\section{Comentario}

La ictericia neonatal es una condición frecuente y autolimitada en la mayoría de los casos; sin embargo, excepcionalmente la hiperbilirrubinemia extrema, aún sin hemólisis, puede conducir a daño cerebral devastador e irreversible. La encefalopatía bilirrubínica o kernicterus debería ser en la actualidad una enfermedad prevenible y erradicada. La reaparición de casos de kernicterus en los últimos años es multifactorial, si bien la aceptación de valores más altos para su tratamiento y el alta más precoz de los recién nacidos (RN) han contribuido a este retroceso.

El estudio de Newman y colaboradores muestra una cohorte de RN de término y casi término con valores de bilirrubina entre 25 y 30 $\mathrm{mg} / \mathrm{dl}$ cuya evolución, desde el punto de vista del neurodesarrollo, fue favorable y similar a la de sus controles sin hiperbilirrubinemia, a los dos años de vida; aunque en la evaluación formal del 5to año la pérdida en el seguimiento es muy elevada para establecer conclusiones valederas. Como los autores marcan, la incidencia de kernicterus es muy baja y por lo tanto este estudio no tiene el poder suficiente para detectar este evento catastrófico; a su vez, la mayoría de los niños se encontraban en valores más cercanos a 25 que a $30 \mathrm{mg} / \mathrm{dl}$. Es importante remarcar que esta evolución corres- ponde a niños con tratamiento establecido.

Con la evidencia actual, es necesario ser prudente y como marcan las Recomendaciones de la Academia Estadounidense de Pediatría ${ }^{1}$ en su nueva revisión sobre el manejo de RN de 35 o más semanas de gestación con hiperbilirrubinemia: considerar individualmente cada caso, evaluar el riesgo prealta mediante el normograma específico, reconocer el manejo diferencial para los RN entre 35 y 37 semanas y establecer una lactancia exitosa como reaseguro de hidratación y nutrición satisfactoria, especialmente en el caso de que el alta se otorgue precozmente.

\section{Conclusiones del Comentador}

El balance entre prevenir las secuelas de la hiperbilirrubinemia y minimizar la sobre-evaluación y el sobre-tratamiento de la ictericia es delicado. Para aquellos a cargo del cuidado de los niños en sus primeros días de vida, conocer los riesgos y el tratamiento de esta entidad aparentemente benigna es una responsabilidad.

Susana Rodríguez [ Neonatología - Coordinación de Investigación Clínica. Hospital J.P Garrahan. Buenos Aires, Argentina. ]

Ver glosario*

Rodriguez S. Evolución favorable a mediano plazo de recién nacidos con bilirrubina elevada. Evid. actual. pract. ambul. 9(6); 172. Nov-Dic 2006. Comentado de: Newman T, Liliestrand P. Jeremy R y col. Outcomes among Newborns with Total Serum Bilirubin Levels of $25 \mathrm{mg}$ per Deciliter or More. N Engl J Med. 2006 May 4;354(18):1889-900. PMID: 16672700

\section{Referencias}

1. American Academy of Pediatrics, Subcommittee on Neonatal Hyperbilirubinemia. Management of hyperbilirubinemia in the newborn infant 35 or more weeks of gestation. Pediatrics 2004; 114:297-316. 